\title{
IMPLEMENTASI SISTEM INFORMASI PADA PENYALURAN JASA SECURITY PADA PT. MITRA GARDA MANDIRI
}

\author{
${ }^{1 *}$ Erna Astriyani, ${ }^{2}$ Harfizar, ${ }^{2}$ Santi Kurniawati \\ 1,2,3 Program Studi Sistem Informasi Universitas Raharja \\ ${ }^{1 *}$ erna.astriyani@raharja.info,${ }^{2}$ harfizar@,raharja.info,,${ }^{3}$ santi.kurniawati@raharja.info
}

\begin{abstract}
Abstrak
PT. Mitra Garda Mandiri Tangerang Selatan merupakan suatu badan usaha yang melakukan penyaluran jasa security yang dibutuhkan di setiap perusahaan, untuk mendukung proses penyaluran jasa security dalam bidang pengembangan teknologi informasi. PT. Mitra Garda Mandiri menyediakan semua sarana pendukung jasa keamanan bagi pihak yang membutuhkan jasa penyaluran security. saat ini PT. Mitra Garda Mandiri melakukan proses hasil seleksi ataupun kegiatan penyaluran masih menggunakan sistem konvensional dalam penyimpanan data yaitu berupa berkas - berkas anggota security. Sehingga prosedur yang berjalan memakan banyak waktu dalam pencarian berkas dan banyak berkas yang rusak karena tidak tersusun dengan rapi. Dengan berbagai kendala tersebut menyebabkan keterlambatan pembuatan laporan sehingga mempengaruhi efisiensi dan keoptimalan kinerja. Adapun tujuan penelitian ini adalah untuk mengetahui kendala atau permasalahan yang ada untuk selanjutnya dicari solusi atas permasalahan tersebut. Beberapa metode yang digunakan penulis dalam membangun sistem menggunakan metode pengumpulan data seperti observasi, wawancara dan studi pustaka, metode analisa menggunakan metode PIECES, metode perancangan menggunakan Unified Modelling Language (UML) dan metode pengujian menggunakan metode Black-box Testing. Dengan tipe Use Case Diagram, Activity Diagram, Class Diagram dan Sequence Diagram. Hasil dari penelitian ini adalah membangun sistem informasi penyaluran jasa security berbasis website yang diharapkan dapat membantu dalam melakukan pengolahan data yang ada pada PT. Mitra Garda Mandiri.
\end{abstract}

Kata kunci: Penyaluran Security, Sistem Informasi, Web Based

\begin{abstract}
PT. Mitra Garda Mandiri in south Tangerang is a business entity that provides security services needed in every company, to support the process of distributing security services in the field of information technology development. PT. Mitra Garda Mandiri provides all means of supporting security services for parties who need security distribution services. currently PT. Mitra Garda Mandiri conducts the selection process or distribution activities that still use conventional systems in data storage, namely files of security members. So that the running procedure takes a lot of time in searching for files and many files are damaged because they are not neatly organized. With these various constraints, it causes delays in reporting, which affects efficiency and performance optimization. The purpose of this study is to determine the existing constraints or problems and then seek solutions to these problems. Some of the methods used by the author in building the system use data collection methods such as observation, interviews and literature studies, analysis methods using the PIECES method, design methods using Unified Modeling Language (UML) and testing methods using the Black-box Testing method. With the types of Use Case Diagrams, Activity Diagrams, Class Diagrams and Sequence Diagrams. The result of this research is to build a website-based security service distribution information system which is expected to assist in processing the existing data at PT. Garda Mandiri partner.
\end{abstract}

Keywords: Security Distribution, Information Systems, web based 


\section{PENDAHULUAN}

Pengelolaan sistem informasi yang cepat dan tepat akan sangat membantu suatu perusahaan untuk dapat memecahkan berbagai permasalahan yang ada maupun untuk pengambilan keputusan sehingga dapat membantu perusahaan tersebut mencapai target tujuannya. Kecepatan penyampaian informasi dan akses data merupakan satu media pendukung suatu perusahaan untuk memenangkan persaingan. Data adalah sesuatu yang belum mempunyai arti bagi penerimanya dan masih memerlukan adanya suatu pengolahan. Data bisa berwujud suatu keadaan, gambar, suara, huruf, angka, matematika, bahasa ataupun simbol-simbol lainnya yang bisa kita gunakan sebagai bahan untuk melihat lingkungan, obyek, kejadian ataupun suatu konsep. Karena data merupakan pendorong penting dalam membuka cara untuk pendekatan bisnis yang optimal dalam ukuran organisasi [1] Karenanya suatu sistem informasi yang tepat dan optimal akan mampu meningkatkan kinerja organisasi, yang pada akhirnya nanti dengan dukungan aspek - aspek yang lain akan mampu mewujudkan suatu kemajuan bagi organisasi tersebut. PT. MGM menyediakan jasa penyaluran security bagi setiap perusahaan yang membutuhkan jasa security dan selalu berusaha mengoptimalkan penggunaan tenaga kerja dan mampu memberikan alternatif yang baik untuk efisiensi biaya dan meningkatkan produktivitas klien. Proses pengolahan data penyaluran security saat ini dilakukan secara manual sehingga memakan waktu banyak untuk penyaluran serta harus menunggu giliran untuk diantar ke tempat perusahaan/unit dan tidak lagi menjadi pilihan utama bagi suatu perusahaan/ unit dalam mencari security secara manual. Sistem Informasi adalah alternative yang paling cocok untuk memberikan data yang sangat akurat dan memiliki tingkat sekuritas yang terjamin.

Dalam menjalankan kegiatan usahanya PT. MGM telah berpengalaman mengelola keamanan di berbagai lokasi dari Perkantoran, Pabrik, Pergudangan, Pertambangan, Tempat Hiburan dengan berbagai kondisi dan karakteristik wilayahnya. Namun beberapa kendala terjadi karena terlalu banyak aktor yang terlibat pada proses penyaluran area kerja security. Di samping itu juga sistem yang berjalan saat ini hanya menggunakan komputer pada saat pembuatan laporan absensi dan penyaluran area kerja yaitu hanya menggunakan Microsoft Excel dan Microsoft Word.

Penelitian sejenis pernah dilakukan oleh Dewi mengenai proses rekrutmen, seleksi, pelatihan, penempatan dan kinerja karyawan pada Bank Mandiri Persero. Pada penelitian ini data dianalisis dengan Structural Equation Model (SEM) dengan program AMOS bertujuan untuk mengetahui pengaruh proses pelaksanaan penempatan terhadap kinerja[2]. Oswald melakukan penelitian pada PT. PLN Area Manado. Penelitian ini bertujuan untuk mengetahui pengaruh kompetensi, penempatan, dan lingkungan kerja terhadap kinerja pegawai pada PT. PLN (Persero) Wilayah Suluttenggo Area Manado[3].

\section{METODE PENELITIAN}

Dalam melakukan penelitian ini data didapatkan melalui wawancara kepada Manager HRD di PT. Mitra Garda Mandiri (MGM) agar data yang diperoleh lebih akurat. Disamping itu dilakukan pula pengamatan secara langsung ke lokasi sumber data dengan cara mengumpulkan data, informasi dan mempelajari catatan serta dokumen yang ada pada PT. Mitra Garda Mandiri (MGM). Sebagai metode Analisa, peneliti menggunakan PIECES sebagai metode untuk menilai sistem yang berjalan pada perusahaan berdasarkan Performance, Information, Economy, Control, Efficiency, serta Service. PIECES merupakan kerangka yang dipakai untuk mengklasifikasikan suatu problem, opportunities, dan directives yang terdapat pada bagian scope definition analisis dan perancangan system[4]. Dengan kerangka ini, dapat dihasilkan hal-hal baru yang dapat menjadi pertimbangan dalam mengembangkan system. Dalam merancang sistem usulan dan menggambarkan system yang berjalan digunakan Unified Modeling Language (UML) sebagai tools, dimana diagram UML yang digunakan adalah Use case Diagram untuk mengenali interaksi aktor dalam suatu sistem dan Class Diagram untuk menggambarkan struktur sistem dari segi pendefinisian kelas-kelas yang akan dibuat untuk membangun system[5]. Kelas memiliki apa yang disebut atribut dan metode atau operasi . untuk menguji system yang diusulkan digunakan black box testing agar dapat diketahui akan kelemahan dari sistem 
pengelolaan dalam penyaluran yang akan dibuat. Urutan atau tahapan penelitian yang dimaksud dapat dijelaskan pada gambar berikut ini.

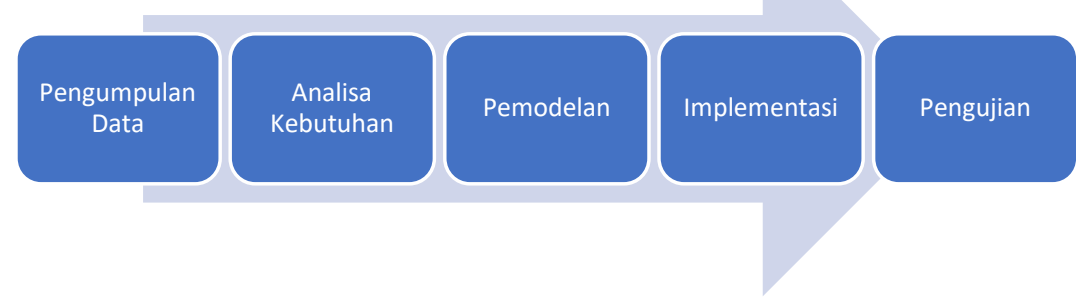

Gambar 1. Tahapan Penelitian

Dalam melakukan Analisa kebutuhan, PIECES dapat mengidentifikasi kelemahan sistem yang menjadi rekomendasi untuk perbaikan-perbaikan yang harus dibuat pada sistem yang akan dikembangkan[6]. Dalam PIECES terdapat enam buah variabel yang digunakan untuk menganalisis sistem informasi. Variable-variabel yang digunakan pada PIECES adalah Performance yang merupakan aspek penting untuk melihat sejauh mana dan seberapa handalkah suatu sistem informasi dalam berproses untuk menghasilkan tujuan yang diinginkan. Variable kedua adalah Informasi untuk melakukan Evaluasi terhadap kemampuan sistem informasi dalam menghasilkan informasi yang bermanfaat perlu dilakukan untuk menyikapi peluang dan menangani masalah yang muncul.

\section{HASIL DAN PEMBAHASAN}

Setelah menganalisis sistem dan penelitian sistem yang berjalan, selanjutnya akan dibahas mengenai rancangan usulan sistem yang akan dibuat. ada beberapa usulan prosedur yaitu, prosedur yang bertujuan untuk memperbaiki dan meningkatkan sistem yang berjalan saat ini. Berdasarkan perubahan sistem yang terjadi saat ini, maka kebutuhan sistem yang baru telah ditentukan, berikut langkah langkah perancangan sistem atau desain sistem usulan yang bertujuan untuk memperbaiki atau merubah sistem yang lama dengan menggambarkan atau pandangan yang jelas proses desain sistem dari awal hingga akhir penelitian. sistem usulan ini menggunakan visual paradigm 16 untuk menggambarkan Use Case diagram, Class Diagram, Activity Diagram, dan Sequence Diagram.

Analisa PIECES dilakukan untuk menilai sistem yang berjalan pada perusahaan berdasarkan Performance, Information, Economy, Control, Efficiency, serta Service. Berikut adalah hasil analisis PIECES yang telah dilakukan:

Tabel 1. Hasil Analisa PIECES

\begin{tabular}{|l|l|l|}
\hline No & Variabel & Hasil Analisa \\
\hline 1. & Performance & $\begin{array}{l}\text { Proses Penyaluran Security ke tempat perusahaan/unit } \\
\text { masih manual sehingga ketika sedang melakukan proses } \\
\text { penyaluran security ke area kerja memakan waktu yang } \\
\text { lama, karena pada proses ini security diharuskan menunggu } \\
\text { giliran namanya dipanggil setelah melakukan absensi. }\end{array}$ \\
\hline 2. & Information & $\begin{array}{l}\text { Akurat: Informasi yang dihasilkan sering terjadi kesalahan } \\
\text { pada proses penyaluran security di tempat area kerja (besar } \\
\text { terjadinya human error), oleh karena itu dibutuhkan sebuah } \\
\text { sistem yang terkomputerisasi. }\end{array}$ \\
\hline 3. & Economy & $\begin{array}{l}\text { Terlalu banyak lembar kertas yang digunakan didalam } \\
\text { proses penyaluran security ke tempat perusahaan/unit, dan } \\
\text { berdampak pada pengeluaran untuk membeli kertas } \\
\text { semakin besar. }\end{array}$ \\
\hline 4. & Control & $\begin{array}{l}\text { Kontrol Sistem: kontrol yang sering terjadi terhadap } \\
\text { penyaluran security adalah seringnya Anggota security }\end{array}$ \\
\hline
\end{tabular}




\begin{tabular}{|l|l|l|}
\hline & & $\begin{array}{l}\text { meminta area kerja yang menurut mereka nyaman dan } \\
\text { menimbulkan kecemburuan sosial terhadap security yang } \\
\text { lainnya. }\end{array}$ \\
\hline 5. & Efficiency & $\begin{array}{l}\text { Sumber daya biaya: adanya kesalahan pada proses mencatat } \\
\text { proses penempatan mengakibatkan kertas yang } \\
\text { digunakannya bertambah. Sumber Daya Tenaga: Proses } \\
\text { penyaluran yang masih manual dan belum terkomputerisasi } \\
\text { yang dilakukan oleh Dansektor, mengakibatkan Dansektor } \\
\text { harus cepat dalam proses penyaluran security ke tempat } \\
\text { area. }\end{array}$ \\
& Service & $\begin{array}{l}\text { Pelayanan sistem yang berjalan saat ini belum } \\
\text { mempermudah Dansektor dalam proses penyaluran } \\
\text { security. Hasil dari analisis PIECES ini menyatakan bahwa } \\
\text { sistem yang saat ini berlangsung tidak optimal dan perlu } \\
\text { dirancangnya sistem Penyaluran Jasa Security Outsourcing } \\
\text { yang terkomputerisasi untuk memudahkan Dansektor } \\
\text { dalam proses penyaluran Security. }\end{array}$ \\
\hline
\end{tabular}

Dari hasil pengumpulan dan analisis data didapatkan informasi mengenai prosedur sistem yang berjalan pada penyaluran jasa security, yaitu Client/Mitra mengirimkan dan mengajukan surat permohonan penyaluran Anggota security yang dibutuhkan perusahaan/unit kepada admin, selanjutnya admin akan melakukan verifikasi pemilihan Anggota security untuk penyaluran jika diverifikasi "Ya" berdasarkan tempat Client/Mitra, dan jika diverifikasi "Tidak" maka admin akan memberikan surat penolakan kepada Client/Mitra. Setelah diverivikasi oleh admin pimpinan melakukan verifikasi, daftar dokumen anggota yang disarankan jika diverifikasi "Ya" oleh admin akan ditandatangani oleh pimpinan. Dan jika diverifikasi "Tidak" maka daftar anggota akan dikembalikan kepada Client/Mitra. Tahap terakhir yaitu admin menyalurkan dan mengirim daftar dokumen anggota untuk diberikan kepada mitra. Alur proses yang dimaksud dapat digambarkan pada diagram berikut :

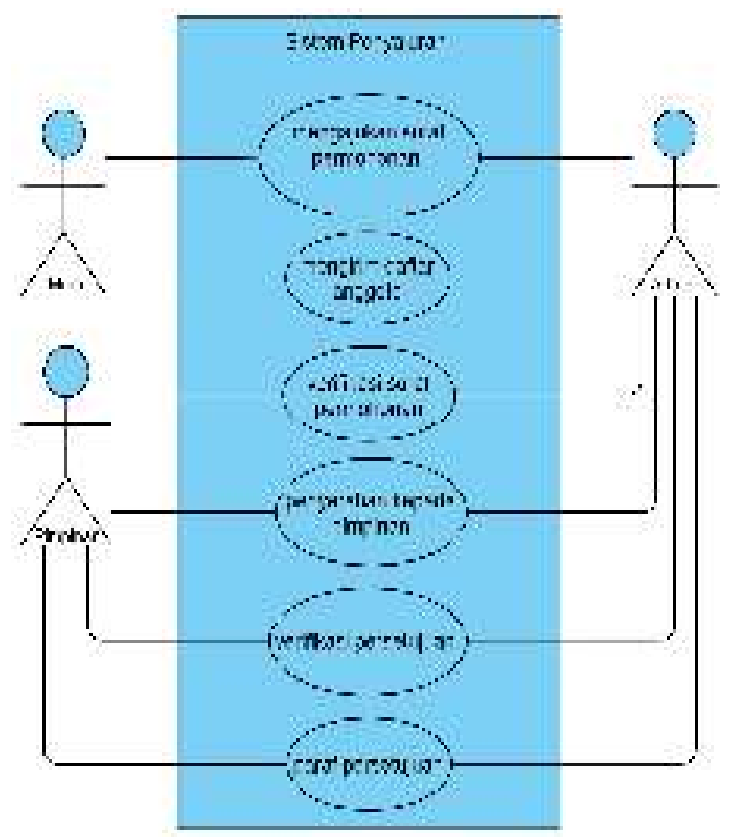

Gambar 2. Use case diagram system berjalan

Berdasarkan diagram dari sistem yang berjalan saat ini, dapat disimpulkan beberapa masalah yaitu bahwa sistem yang berjalan saat ini hanya menggunakan sistem manajemen pengolahan data penyaluran tenaga kerja security secara manual. Di samping itu juga banyak aktor yang terlibat padahal 
ada proses yang bisa disederhanakan sehingga kurang efisien. Sistem yang berjalan saat ini juga hanya menggunakan komputer pada saat pembuatan laporan absensi dan penyaluran area kerja yang hanya menggunakan Microsoft Excel dan Microsoft Word sehingga pihak manajemen kesulitan apabila sewaktu-waktu dibutuhkan laporan atau data security dengan cepat. Dengan demikian perlu di cari solusi dari permasalahan yang terjadi. maka peneliti mengusulkan solusi pemecahan masalah yang dihadapi, yaitu:

a. Membuat sistem penyaluran area kerja security yang terkomputerisasi seluruhnya, agar memudahkan pembuatan laporan dan mudah dalam pencarian dokumen/laporan, karena sudah ada dalam satu database.

b. Aktor yang dimudahkan dengan sistem yang terkomputerisasi dan tidak banyak tugas yang dijalani dalam penempatan area kerja.

c. Sistem yang berjalan mencakup kegiatan penyaluran area kerja security dan output laporan yang sudah menggunakan sistem yang terkomputerisasi.

Dari hasil diskusi dengan pihak stakeholder didapatkan kebutuhan dari aplikasi yang akan dibuat nanti. Adapun aplikasi yang akan dibuat nanti adalah sistem penyaluran jasa security berbasis website. Karena aplikasi berbasis berbasis website dapat berjalan pada semua platform atau system Operasi karena yang dibutuhkan hanya browser. Menurut maulani website adalah suatu layanan sajian informasi yang menggunakan konsep hyperlink (tautan) dengan menggunakan media untuk memudahkan surfer (sebutan para pemakai komputer yang melakukan browsing atau penelusuran informasi melalui internet) di dalam pencarian informasi [7]. Untuk mendukung aplikasi tersebut digunakan MySQL sebagai databasenya. MySQL merupakan software RDBMS (software database) yang dapat mengelola database dengan sangat cepat, dapat menampung data dalam jumlah sangat besar, dapat diakses oleh banyak user (multi-user), dan dapat melakukan suatu proses secara sinkron atau berbarengan (multi-threaded)[8]. Spesifikasi kebutuhan untuk aplikasi yang akan dibuat nanti disajikan pada tabel berikut ini :

Tabel 2. Analisa Kebutuhan Sistem

\begin{tabular}{|l|l|}
\hline Functional \\
\hline \multirow{2}{*}{ No } & Analisa Kebutuhan \\
\cline { 2 - 3 } & Saya ingin sistem dapat \\
\hline 1. & Memiliki halaman login \\
\hline 2. & Menampilkan pesan kesalahan jika user menginput password yang salah \\
\hline 3. & Memiliki tampilan dashboard \\
\hline 4. & Menampilkan logo perusahaan \\
\hline 5. & Memiliki fasilitas pengolahan data karyawan \\
\hline 6. & Memiliki fasilitas pengolahan data mitra \\
\hline 7. & Memiliki fasilitas pengolahan data penyaluran \\
\hline 8 & Memiliki fasilitas view surat pernyataan tugas \\
\hline 9. & Memiliki fasilitas download surat pernyataan tugas \\
\hline 10. & Memiliki fasilitas view surat pernyataan \\
\hline 11. & Memiliki fasilitas download surat pernyataan \\
\hline 12. & Memiliki fasilitas pencarian data \\
\hline 13. & Memiliki fasilitas update biodata karyawan \\
\hline 14. & Memiliki fasilitas ubah password \\
\hline 15. & Memiliki fasilitas logout sistem \\
\hline Non Functional \\
\hline \multirow{2}{*}{ No } & Analisa Kebutuhan \\
\cline { 2 - 3 } & Saya ingin sistem dapat \\
\hline 1. & Bersifat user friendly \\
\hline 2. & Memiliki tampilan yang menarik \\
\hline 3. & Tampilan website bersifat responsiv \\
\hline 4. & Menggunakan MySQL sebagai database \\
\hline
\end{tabular}


Setelah didapatkan kebutuhan untuk aplikasi maka selanjutnya pelu di definisikan alur proses untuk system yang diusulkan termasuk hak akses dari tiap penggunanya. Prosedur sistem usulan pada penyaluran area kerja security dapat dijelaskan sebagai berikut:

Tabel 2. Hak akses pengguna

\begin{tabular}{|l|l|}
\hline \multirow{2}{*}{ No } & Hak Akses admin \\
\cline { 2 - 3 } & Admin dapat melakukan kegiatan keseluruhan hak akses dalam sistem, yaitu \\
\hline 1. & Admin dapat melakukan login \\
\hline 2. & Menambah user sesuai hak yang telah ditentukan \\
\hline 3. & $\begin{array}{l}\text { Admin dapat menampilkan semua menu yang ada dalam sistem, yaitu mulai dari } \\
\text { dashboard, master lokasi unit/ perusahaan, shift, security, area penyaluran security dan } \\
\text { user. }\end{array}$ \\
\hline 4. & $\begin{array}{l}\text { Dapat melakukan input data lokasi, unit/perusahaan, shift, anggota security, unit } \\
\text { anggota security, }\end{array}$ \\
\hline 5. & $\begin{array}{l}\text { Dapat menghapus data lokasi, Unit, Shift, Anggota Security dan Unit Anggota } \\
\text { Security }\end{array}$ \\
\hline 6. & Dapat melakukan Print / cetak laporan \\
\hline 7. & Dapat melakukan logout. \\
\hline No & Hak Akses Anggota Security \\
\cline { 2 - 3 } Anggota security mempunyai akses sebagai berikut : \\
\hline 1. & Dapat melakukan Login \\
\hline 2. & Dapat melakukan perubahan data profil Anggota Security \\
\hline 3. & Dapat membuat surat pernyataan \\
\hline 4. & Dapat membuat surat pernyataan siap tugas \\
\hline 5. & Dapat melakukan Logout. \\
\hline
\end{tabular}

Aplikasi yang dibangun bersifat multi user, dimana terdapat lebih dari satu user yang dapat mengakses system tersebut. Setiap pengguna dibedakan berdasarkan hak aksesnya dan setiap pengguna memiliki akun masing-masing yang terdiri atas username dan password. Aktifitas keseluruhan dari hak akses tiap user dapat digambarkan dengan menggunakan diagram dibawah ini

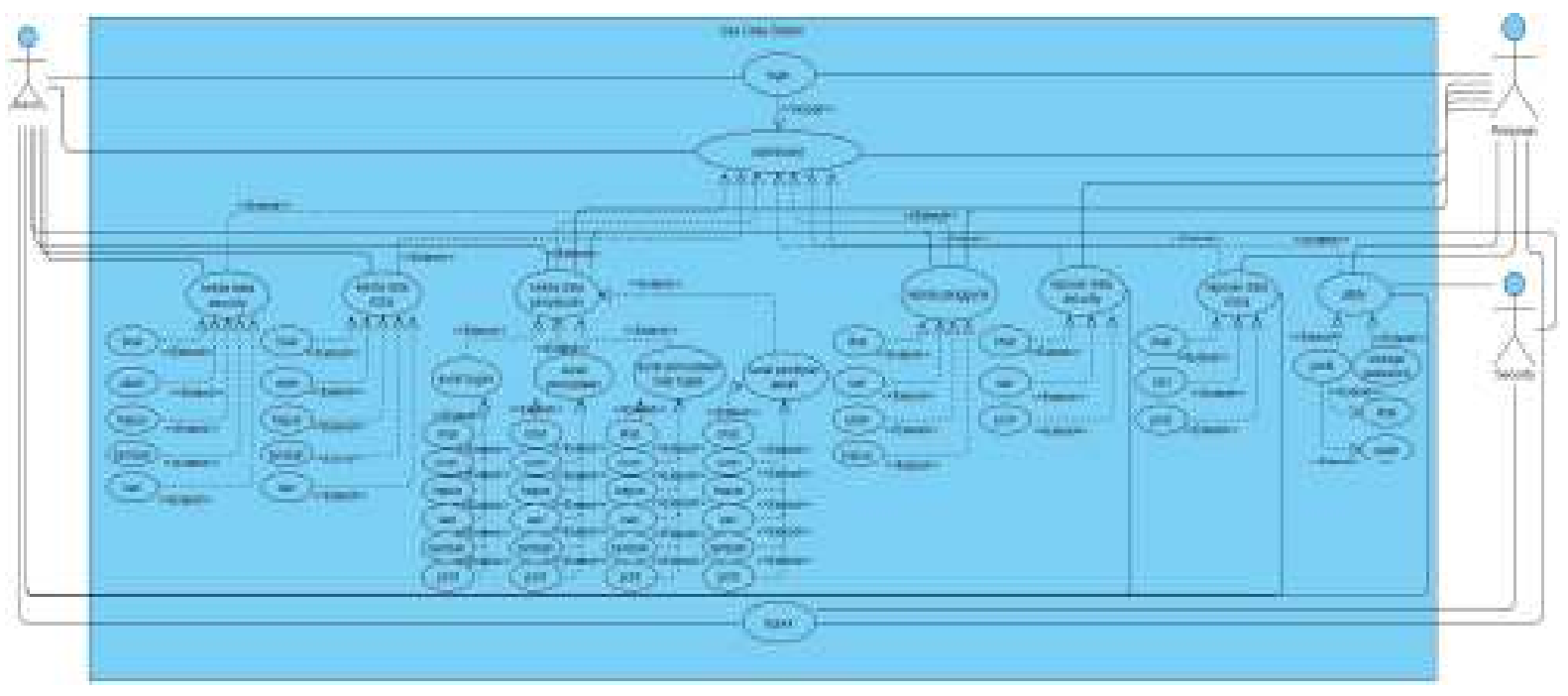

Gambar 3. Use case diagram system usulan 
Untuk dapat menggambarkan bentuk basis data secara utuh, peneliti penggunakan aplikasi MySQL yang dijalankan dengan PHP MyAdmin sebagai bentuk gambaran dasar, dan pada akhirnya bentuk rancangan basis data ini dapat disesuaikan menggunakan apa saja sesuai kebutuhan.

\section{a. Tabel Master: bagian}

Primary Key : kd_bagian

Foreign Key : : -

Structure Tabel : $\{$ kd_bagian, nm_bagian $\}$

Tabel 3. Struktur tabel bagian

\begin{tabular}{|c|l|l|l|l|}
\hline No & \multicolumn{1}{|c|}{ Nama Field } & Tipe Data & Field Size & \multicolumn{1}{|c|}{ Ketcrangan } \\
\hline 1 & Kd bagian & int & 2 & Primcry hey \\
\hline 2 & 1an bagizal & yauchar & 100 & \\
\hline
\end{tabular}

b. Tabel Master: karyawan

Primary Key : : id

Foreign Key : : -

Structure Tabel :

\{id,nik,nm_karyawan,kd_bagian,password,kelamin,gol_darah,agama,alamat_tinggal,no_telepo n,tempat_lahir,tanggal_lahir,status_kawin,tanggal_masuk,ttd,foto \}

Tabel 4. Struktur tabel karyawan

\begin{tabular}{|c|c|c|c|c|}
\hline $\mathrm{No}$ & Nams Fieid & Tipe Data & Fletó Size & Keteraugan \\
\hline I & Id & int & 5 & Primary key \\
\hline 2 & nik & varchar & 20 & \\
\hline 3 & un karviansu & vatchat & 100 & \\
\hline 4 & $\mathrm{kd}$ hagian & int & 3 & \\
\hline 5 & password & varchar & 50 & \\
\hline 6 & belunin & varbar & 10 & \\
\hline 7 & eol darah & exum & & \\
\hline 8 & agimna & Garchar & 20 & \\
\hline 9 & dezont_taiggul & vantuaz & 100 & \\
\hline 10 & no telepon & varchar & 20 & \\
\hline 11 & šutpul_alnir & vartus: & 40 & \\
\hline 12 & tangral lahir & date & & \\
\hline 13 & stants kawin & cman & & \\
\hline 14 & tanggal masuc & date & & \\
\hline IS & ntd & varchar & 30 & \\
\hline 16 & fols & varbar & 30 & \\
\hline
\end{tabular}

\section{c. Tabel Master: mitra}

Primary Key : id_mitra

Foreign Key : -

Structure Tabel : \{id_mitra,nama_mitra.alamat.no_telpon.kota.logo $\}$ 
Tabel 5. Struktur Tabel Mitra

\begin{tabular}{|c|l|l|l|l|}
\hline No & \multicolumn{1}{|c|}{ Nama Fiejd } & \multicolumn{1}{|c|}{ Tipe Data } & \multicolumn{1}{|c|}{ Fieid Size } & Ketcrangan \\
\hline 1 & id_mirra & int & 3 & Primary key \\
\hline 2 & nama mitra & varchar & 25 & \\
\hline 3 & alamat & varchar & 200 & \\
\hline 4 & no telpon & varchar & 15 & \\
\hline 5 & kota & varchar & 30 & \\
\hline 6 & logo & varchar & 100 & \\
\hline
\end{tabular}

d. Tabel Master: user

Primary Key $\quad$ : kd_user

Foreign Key : -

Structure Tabel : $\{$ kd_user,nm_user,no_telepon,username,password,level $\}$

Tabel 5. Struktur Tabel user

\begin{tabular}{|c|l|l|l|l|}
\hline No & \multicolumn{1}{|c|}{ Nama Field } & \multicolumn{1}{|c|}{ Tipe Data } & \multicolumn{1}{|c|}{ Field Size } & Keterangan \\
\hline 1 & kd user & char & 14 & Primary hey \\
\hline 2 & nm user & varchar & 100 & \\
\hline 3 & no tclepon & varchar & 20 & \\
\hline 4 & username & varchar & 20 & \\
\hline 5 & password & varchar & 200 & \\
\hline 6 & level & varchar & 20 & \\
\hline
\end{tabular}

e. Tabel Transaksi: penugasan

Primary Key : : id

Foreign Key : id_mitra,nik

Structure Tabel :

id,no_penugasan,id_mitra,nik,tgl_penugasan_awal,tgl_penugasan_akhir,tgl_post,kd_user\}

Tabel 6. Struktur tabel penugasan

\begin{tabular}{|c|c|c|c|c|}
\hline Nis & Nama Freid & Tige Dafa & Field Size & Keterangan \\
\hline 1 & id & int & 15 & Priming ket \\
\hline 2 & no peumeasan & varchar & 30 & \\
\hline 3 & id mitra & Vatchar & 3 & \\
\hline 4 & nik & varchar & 10 & \\
\hline 5 & tgl penugasan_awal & date & & \\
\hline 6 & tgl penugasan akhir & date & & \\
\hline 7 & tol post & date & & \\
\hline 8 & ki_user & varchat & 15 & \\
\hline
\end{tabular}

\section{f. Tabel Transaksi: surat}

Primary Key : : id

Foreign Key : id_penugasan,nik

Structure Tabel : $\{$ id,id_penugasan,nik,spst,pernyataan,tugas\} 
Tabel 7. Struktur tabel surat

\begin{tabular}{|c|l|ll|l|}
\hline No & \multicolumn{1}{|c|}{ Nama Fieid } & Tipe Data & Fleid Size & Keterangan \\
\hline 1 & id & iut & 5 & Primary key \\
2 & id penugasan & int & 5 & \\
\hline 3 & unk & varchar & 12 & \\
1 & spst & varchar & 1 & \\
5 & penvyataan & varchar & 1 & \\
\hline 6 & tugas & vurchar & 1 & \\
\hline
\end{tabular}

Implementasi sistem informasi penyaluran jasa security yang diaplikasikan dalam bentuk website dapat dilihat pada tampilan berikut ini. dimana terdapat halaman login untuk tiap user atau hak akses, begitu juga halaman-halaman lain yang sudah didefinisikan sesuai kebutuhan pengguna..

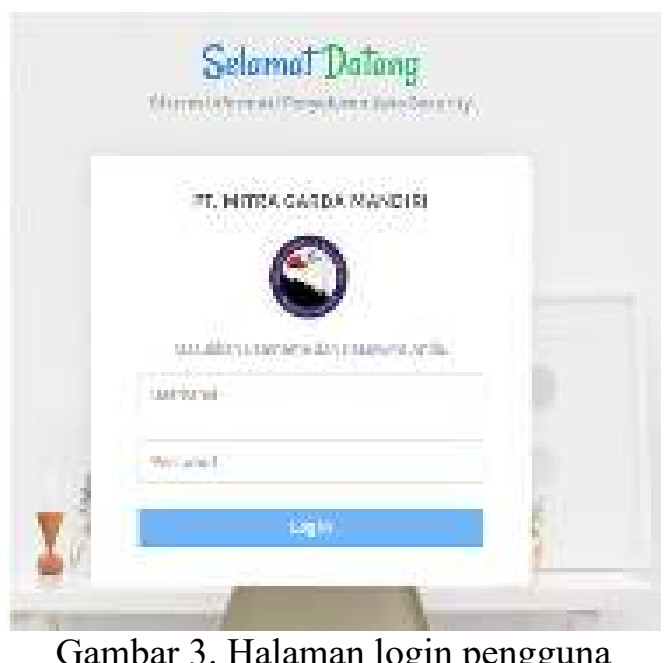

Pada halaman ini pengguna harus memasukkan username dan password yang valid sesuai yang tedaftar pada database. Setelah berhasil login maka akan di tampilkan halaman utama beserta menu-menu berdasarkan hak aksesnya.

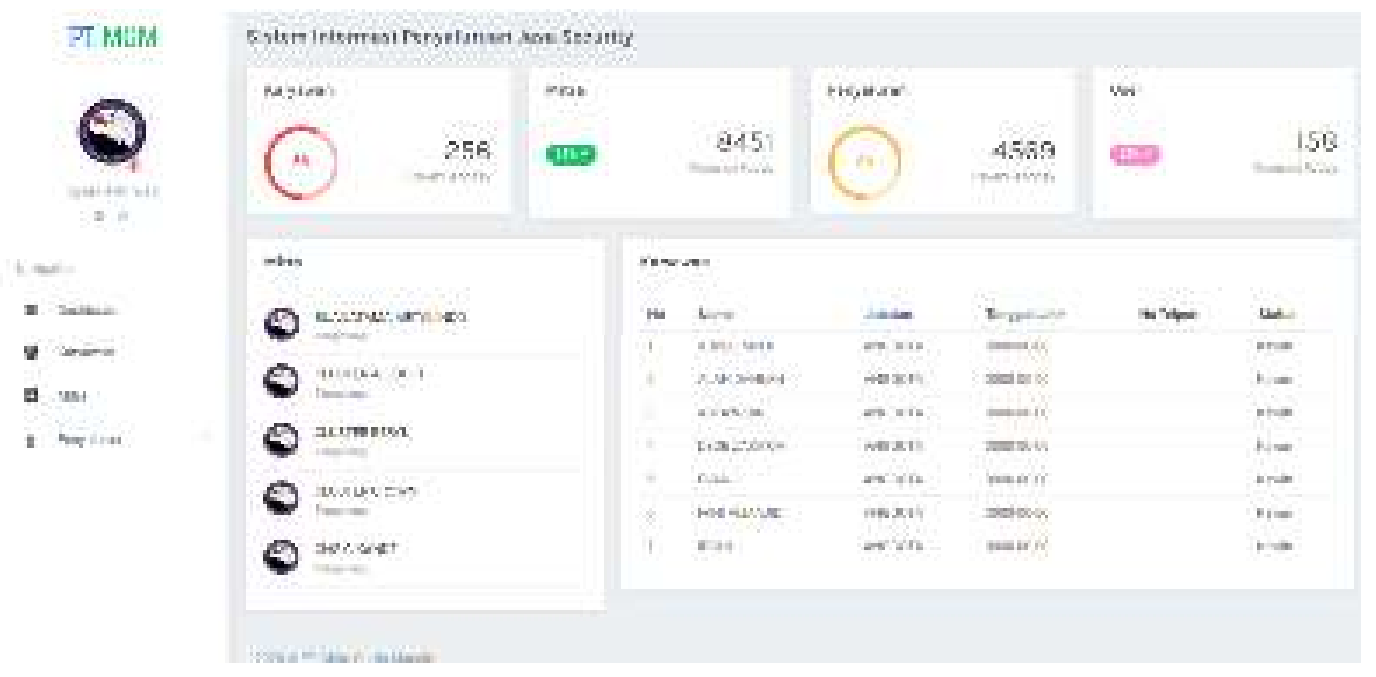

Gambar 4. Halaman Utama Admin 
Seperti yang terlihat pada gambar 4, admin dapat melakukan pengolahan data karyawan, mitra dan penyaluran. Pada halaman utama juga ditampilkan jumlah data karyawan, mitra penyaluran dan user. Pada halaman ini juga admin dapat melihat anggota security yang sudah menyerahkan surat pernyataan dan surat pernyataan siap tugas.

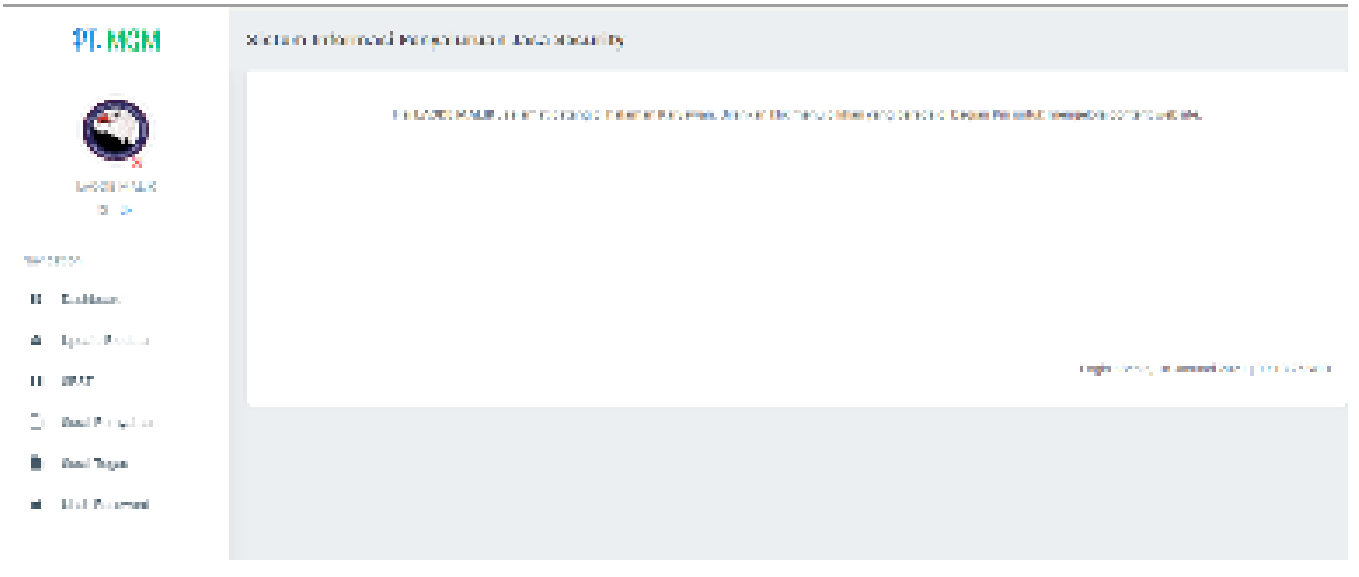

Gambar 5. Halaman Utama Anggota Security

Untuk memudahkan anggota security dalam melakukan update biodata, terdapat pula fitur update biodata yang dapat diakses dari menu karyawan, sehingga anggota security dapat melakukan update biodata secara mandiri apabila terdapat perubahan data pada masing-masing anggota. Untuk menyerahkan surat tugas, anggota security tidak perlu lagi mengambilnya pada bagian HRD karena anggota dapat langsung mengirimkan surat pernyataan siap tugas dan surat pernyataan melalui aplikasi hanya dengan menekan tombol kirim. Disamping itu setiap anggota juga dapat mendownload surat tugas apabila admin sudah melakukan penugasan untuk anggota security tersebut.

Setelah aplikasi berhasil dibuat, selanjutnya adalah melakukan pengujian terhadap aplikasi tersebut. Pengujian dilakukan dengan menggunakan blacbox testing. Blackbox Testing merupakan metode pengujian suatu program yang mengutamakan kebutuhan fungsi dari program tersebut. Dalam metode Blackbox Testing menemukan kesalahan fungsi dari suatu program merupakan tujuan dalam metode ini. Metode Blackbox Testing hanya mengamati hasil eksekusi melalui data uji dan memeriksa fungsionalitas dari sebuah program tanpa melihat dan mengetahui yang terjadi dalam prosesnya, melainkan berupa input dan output. Tabel pengujian dengan blackbox testing disajikan pada tabel berikut ini : 
ISSN : $2356-5195$

Online ISSN: 2654 - 8704

Tabel 8. Pengujian Black Box

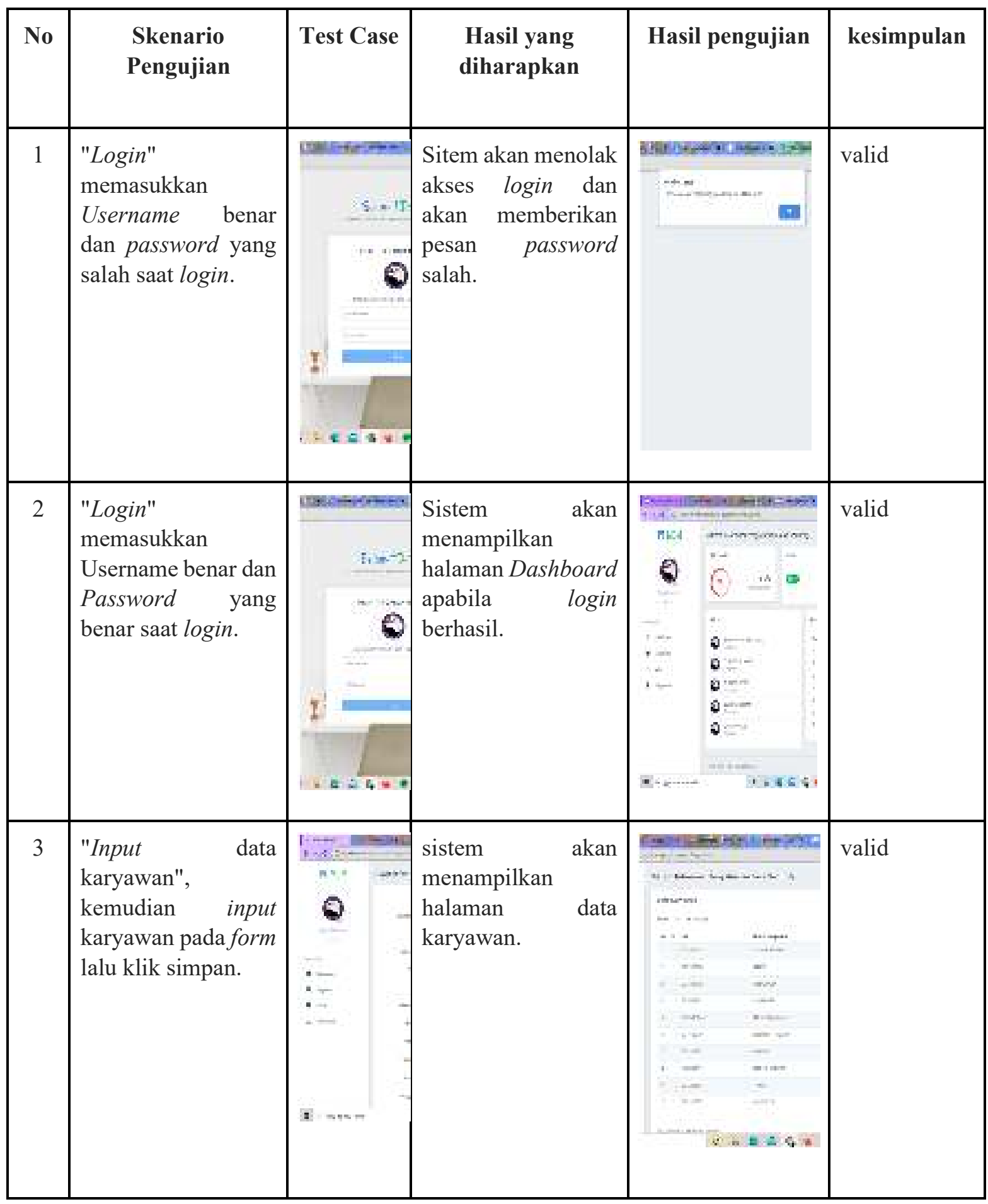




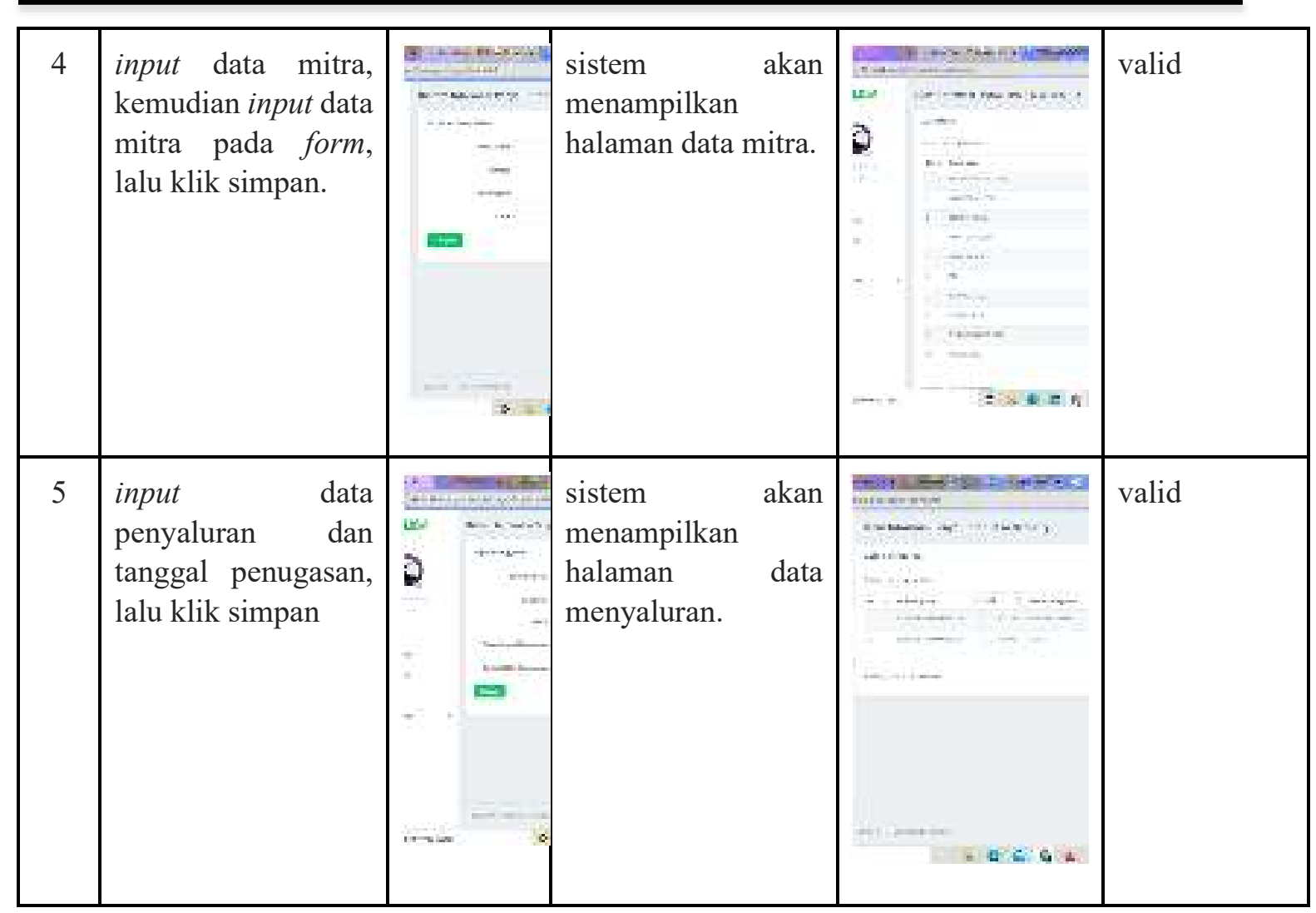

Setelah dilakukan pengujian sistem menggunakan metode Blackbox Testing dengan cara memberikan sejumlah input pada program seperti contoh pada pengujian menu Login, input karyawan, input penyaluran, menu mitra dan menu SPST. Jika input yang yang diberikan tidak lengkap atau tidak sesuai, maka sistem akan memberikan pemberitahuan tampilan pesan sehingga membantu pengguna dalam mencari dan mengetahui letak kesalahan saat penginputan. Dari beberapa pengujian yang sudah dilakukan menggunakan metode blackbox testing seluruhnya menunjukan pengujian yang valid atau berhasil.

\section{Kesimpulan}

Berdasarkan hasil analisa sistem yang sedang berjalan dan juga berdasarkan hasil dari pengamatan peneliti terhadap rumusan masalah yang ada, maka dapat diambil kesimpulan bahwa sistem penyaluran Security di PT. MGM masih belum memiliki sistem terkomputerisasi yang memudahkan para pimpinan dalam penyaluran ke mitra, sehingga belum berjalan dengan cepat pada prosesnya. Informasi yang dihasilkan sering terjadi kesalahan pada proses penyaluran security di tempat area kerja (besar terjadinya human error). Karena masih berjalan dengan sistem manual dan belum memiliki tempat penyimpanan data sehingga masih sering terjadi kehilangan data yang menimbulkan masalah pada saat pencarian data, maka diperlukan perangkat database agar data tersimpan dengan baik. Dengan menggunakan system informasi dapat memudahkan pembuatan laporan dan mudah dalam pencarian dokumen/laporan, karena sudah ada dalam satu database. Perusahaan juga dimudahkan dengan sistem yang terkomputerisasi dan tidak banyak tugas yang dijalani dalam penempatan area kerja.

\section{DAFTAR PUSTAKA}

[1]. Kanal, Abhisek; Aishwarya;. (2016). "Data Analysis And Business Modelling In Microsoft Excel Using Analysis Tollpax". In International Journal Of Computer Science And Information Technologies. 
[2]. A.A. Inten Suastika Dewi dan Gede Sri Darma, 2017, Undiknas Graduate School, dalam jurnal Manajemen dan Bisnis, Vol. 14

[3]. Oswald H F Pokatong, Lisbeth Mananeke dan Sjendri Loindong, dalam Jurnal EMBA Vol. 3, No. 2 Juni 2015.

[4]. Supriyatna, Adi, Vivi Maria. 2017. Analisis Tingkat Kepuasan Pengguna dan Tingkat Kepentingan Penerapan Sistem Informasi DJP Online dengan Kerangka PIECES. Khazanah Informatika Volume 3 No. 2 | ISSN : 2477-698X.

[5]. Tri Hartati dalam jurnal Taknik dan Ilmu Komputer 2017:185

[6]. Suyono, A. A., Indianiati, U. N., Rizki, E. M., Hamidah, S., \& Jannah, E. N. (2016). Analisis Aplikasi Integrated Postal Operations System (IPOS) Pada PT. Pos Indonesia (Persero) KPRK Jombang Menggunakan Metode PIECES. Register: Jurnal Ilmiah Teknologi Sistem Informasi, $2(1), 22-33$.

[7]. Maulani, G., Buana Sejati, K. C., \& Pujianingsih, S. (2016). Sistem Informasi Pengelolaan Data Pembinaan Kegiatan Kerja Narapidana Berbasis Website pada Lembaga Pemasyarakatan Kelas Iia Pemuda Tangerang. Innovative Creative and Information Technology, 2(1), 1-14.

[8]. Nofyat, Adelina Ibrahim dan Arisandy Ambarita. 2018. Sistem Informasi Pengaduan Pelanggan Air Berbasis Website Pada PDAM Kota Ternate. Indonesian Journal On Information System, Hal: 10-19. 